\title{
Article
}

\section{Stakeholder Diversity versus stakeholder General Views: A Theoretical Gap in Sustainability Materiality Conception}

\author{
Yining Zhou ${ }^{1, *}$ and Geoff Lamberton ${ }^{2}$
}

\author{
${ }^{1}$ Southern Cross Business School, Southern Cross University, Riverside Campus, Tweed Heads, New \\ South Wales, Australia. \\ ${ }^{2}$ Southern Cross Business School, Southern Cross University, Beachside Campus, Gold Coast, \\ Queensland, Australia. \\ Emails: yining.zhou@scu.edu.au; glambert@scu.edu.au. \\ * Author to whom correspondence should be addressed; Tel: +61 451058411 \\ Received: / Accepted: / Published:
}

\begin{abstract}
Over the last decade, since GRI (G3) launched its definition on materiality, the materiality concept has been widely applied in corporate sustainability reports and management. The definition of 'materiality' in sustainability context is based on extending the content of definition of 'financial materiality': financial materiality is about the significance of financial information towards investors; whilst materiality in sustainability context targets on issues significant to a wider extent of stakeholders including not only investors, but also communities, employees, customers, governments, non-government organizations, and so on. Current definitions on sustainability materiality are to take all stakeholders as a whole, towards whom an


issue is material (see GRI G3 and AA 1000). That is, the materiality of sustainability issues is based on the general views of stakeholders: the issue is material because stakeholders generally accept it as material. However, such materiality conception ignores or oversights the diversity in stakeholders, a basic assumption in stakeholder theory. The diversity reflects as their different relationships to an organization, and lies in the different or conflicting values, expectations and interests among stakeholders.

From this perspective, a theoretical gap exists in prior materiality models and research, which do not address 'stakeholder diversity'. This study argues that a new way on defining materiality is to fix this gap. It further proposes a 'hierarchy of materiality' model, which may put insights for future research.

Keywords: sustainability, materiality, stakeholder, stakeholder diversity, sustainability reports

\section{Introduction}

A critical question in sustainability accounting is the conception of materiality in sustainability context. Over the last decade, since GRI (G3) launched its definition on materiality, the materiality concept has been applied in businesses sustainability reports and management. The definition of 'materiality' in sustainability context is based on extending the content of definition of 'financial materiality': financial materiality is about the significance of financial information towards investors; while materiality in sustainability context targets on issues that are significant to a wider extent of stakeholders including not only investors, but also communities, employees, customers, governments, etc.

Current definitions on sustainability materiality remains in taking 'stakeholders' as a whole, to who an issue is material [18] [1] [35]. However the diversity of stakeholders tends to be ignored by these definitions. The diversity lies in the different or even conflicting interests, actions and views on this issue. 
I believe a fundamental question needs to be addressed: how the diversity of stakeholders affects the materiality assessment of sustainability issues? I examine this question in this conceptual paper that focuses on primary data.

The objective of this research is to fix the theoretical gap in prior research on sustainability materiality. Prior research often views stakeholders as a uniform unit but ignores the diversity among them. To achieve this objective, the study formulates a new materiality model in which multiple stakeholder interests and divergent issue impacts are incorporated. It thus potentially generates new thinking to challenge the traditional views, and enriches the theory of sustainability accounting.

\section{Sustainability, Organizational Sustainability and Stakeholder}

The notion 'sustainability' is often referred to 'sustainable development', which is considered a modern crusade when its definition was firstly released by the Brundtland Report 1987, where sustainable development is defined as "development that meets the needs of the present without compromising the ability of future generations to meet their own needs" [6]. However, for whether sustainability or sustainable development, clarification of the concept proves difficult, and there is no agreed and generally accepted definition [24] [11]. But it is worthy observing that 'sustainability' is often conceptualized as a synthesis of ecological, social and economic goals [24] [25], which require people to live better in and from the richness of the economic and social system and ecosystem [29].

The concept of sustainability can be applied in organizational level, and finds its equivalent in the term corporate sustainability or organizational sustainability [32]. Corporate sustainability is viewed as to posing an alternative to the traditional models of short-term wealth maximization [34] [32], to 'shift organizations' focus from an exclusively financially oriented perspective and respond to the challenge of sustainable development' [24].

A stakeholder is 'any group or individual who can affect or is affected by the achievement of the organization's objectives" [16]. Stakeholder theory posits a model of an organization in which 'all persons or groups with legitimate interests ns or groups with legitimate interests participating in an enterprise do so to obtain benefits, and there is no primary priority of one set of interests and benefits 
over another" [12]. The model that stakeholder theory posits rejects the idea that "the enterprise exists to serve the interest of its owners, as to maximizing their wealth or some other reason for being in business' [33]. Rather, such a model is based on the idea that 'the enterprise exists to serve the many stakeholders who have an interest in it or who in some way may be harmed or benefitted by it' [33].

The notion of 'stakeholder management' for organizational sustainability has been described as an organization behaving in such a way as to satisfy the needs and expectations of its stakeholders [17] [15]. To achieve organizational sustainability, 'organizations should aim to satisfy, or preferably exceed, the wants and expectations of its stakeholders without compromising the ability of other parties to meet their needs' [15].

\section{Diversity in Stakeholders}

Donaldson and Preston [12] point out that stakeholder theory may be stated in descriptive, instrumental, or normative terms. Weiss [33] provides two examples to explain the first two terms: on descriptive terms, Brenner and Cochran [5] offer a stakeholder theory to 'describe how organizations operate and to help predict organizational behavior'; while on instrumental terms, Freeman [16] employs stakeholder theory to develop an instrumental approach to managerial, especially strategic practice.

But in views of Donaldson and Preston [12], stakeholder theory is essentially normative. In consistence with Donaldson and Preston [12], Flak, Nordheim and Munkvold [14] note the normative elements as 'normative assumptions': every organization has a variety of stakeholders and the organizations have moral and ethical duties to know and respect the interests of their stakeholders.

The variety or diversity of stakeholders reflects on the identification and classification of stakeholders in prior research. For example, researchers [16] [5] [21] [10] [7] list stakeholders as diverse constituencies including stockholders, employees, customers, suppliers, governments, trade associations, activists groups, communities, general public, and so on. There are some different classification approaches on these stakeholders. Clarkson [10] identifies those who have 'strong influence' on the organization as 'primary stakeholders' such as employees, shareholders, suppliers and 
customers; while others with weak influence as 'secondary stakeholders' including media, and various interest groups. Some researchers identify managers and employees and investors as internal stakeholders'; while others as external stakeholders.

Diversity of stakeholders can be recognized as their different relationships to an organization in terms of instrumental value. Burton and Dunn [8] use the notions 'instrumental value' and 'relationships with the organizations' to describe how a stakeholder is identified: business-related stakeholders who have instrumental value to the organization are apparent to observers; but some non-business groups (e.g. local communities) with little instrumental value should also be included, because they have legalistic relationships with the organization. From Burton and Dunn [8], the relationships between stakeholders and an organization are essential but different instrumentally. These 'different essential instrumental' relationships reflect on stakeholder diversity.

Mitchell et al [27] develop a theory of stakeholder identification and salience by bringing together three social science concepts to characterize stakeholders: power, legitimacy and urgency, which they labeled stakeholder attributes. They define stakeholder salience as 'the degree to which managers give priority to competing stakeholder claims' [27]. Power is the ability or potential ability of stakeholders to impose their view on a given relationship through coercive, utilitarian, or normative means [27]; a legitimate stakeholder is one whose actions and claims are seen as appropriate, proper, and desirable in the context of the social system [27]; and urgency is the degree to which a stakeholder believes its claims are time sensitive or critical. Based on the three characteristics, Mitchell et al [27] develop a typology of eight types based on whether or not a stakeholder has power, legitimacy and /or urgency. The central relationship in their theory is that the more attributes a stakeholder had, the greater its salience would be. Mitchell et al [27] further suggest that stakeholder attributes are variable, not steady state. This variable attributes and unsteady state are attributed to diversity of stakeholders.

Some researchers [28] discuss the conflict of interests between different stakeholders as a major contention of stakeholder theory. They consider differing worldviews of multiple stakeholders as a primary cause for these conflicts. Mitchell et al [27] mentions that different and often conflicting values and expectations are usually involved in resource allocations and use decisions. Such differences frequently reflect different worldviews, needs and expectations. Sadler and Armour [31] 
stressed the importance of differences in values and interests that exist in a pluralistic society with respect to the use and management of land, water and other natural resources. According to them, dispute settlement is usually difficult to achieve for two interrelated reasons: first, the benefits and costs are unevenly distributed and include intangibles that are hard to evaluate and compare; and second, many affected and interested parties with diverse views and interpretations are often involved [13].

The interests of stakeholder groups are wide and diverse, and failure by companies to address these interests may be detrimental to their performance [10] [16] [20] [30]. However, attempting to address the interests of all stakeholder groups may be precluded by the scarcity of current resources [3] [4] [19] [26].

Freeman [16] proposes a stakeholder map, which describes the wide range of stakeholder groups associated with companies, such as shareholders, employees, consumers, competitors, unions and suppliers. This map represents a wide and diverse range of interests [10] [20], given that each stakeholder group has its own unique set of expectations, needs and values [22]. This diversity of interests creates a potential problem, as failure to address this range of interests may be detrimental to the achievement of an organization's purpose and performance [10] [16] [20] [30], as defined by the organization's executives in its mission and objectives. From an ethical point of view it is also argued that companies have responsibilities and obligations to their stakeholder groups [10] [21]. Again, failure to meet these responsibilities and obligations may be detrimental to corporate purpose and performance, irrespective of the ethical issue. However, attempting to address the interests of all groups may not be possible, because of scarcity of current resources [3] [4] [19] [26] and difficult decisions about their allocation among stakeholders, and because of acquisition of additional resources. It is also theorized that associations between stakeholder management and performance will be influenced by the market environment [10] [23], which enhances the complexity of decision making to address stakeholder interests.

\section{New Materiality and Stakeholder View}

Materiality is one of the most pervasive concepts in accounting practice. It often plays a role in 
determining what accounting information is made public through accounting channels. For example, the Financial Accounting Standards Board (FASB)'s definition of materiality demonstrates an orientation to the users of financial statement: 'The magnitude of an omission or misstatement of accounting information that, in the light of surrounding circumstances, makes it probable that the judgment of a reasonable person relying on the information would have been changed or influenced by the omission or misstatement.' (Statement of financial accounting concepts, No. 2, FASB, 1980)

Typically, understanding and defining materiality focuses on the user perspective. Securities and Exchange Commission (SEC) defines that 'the term 'material,' when used to qualify a requirement for the furnishing of information as to any subject, limits the information required to those matters as to which an average prudent investor ought reasonably to be informed before purchasing the security registered'. And from another institution, American Accounting Association Committee on Concepts and Standards (1954), it states that 'an item should be regarded as material if there is reason to believe that knowledge of it would influence the decisions or attitude of an informed investor'.

The notion of materiality is defined traditionally in the economic context, with definitional content on financial information, and 'users' on financial providers especially investors. But in an extend context of sustainable development where the scope is broadened to cover environmental and social aspects, the definition of materiality needs to be reassessed.

GRI (G3) and AA1000 define materiality on a wider stakeholder perspective, compared to financial materiality focusing on investors.

"The information in a report should cover topics and indicators that reflect the organization's significant economic, environmental, and social impacts or that would substantively influence the assessments and decisions of stakeholders" [18]

'Whether the Reporting Organization has included in the report the information about its sustainability performance required by its stakeholders for them to be able to make informed judgments, decisions and actions.' [1]

Apart from the above institutions on sustainability accounting standards setting, researchers also identify a critical and significant difference between financial materiality and 'new materiality' lying 
on the stakeholder scope. For example, Zadek and Merme [35] and AccoutAbility [2] state: while financial materiality concerns investors, new materiality concerns a wider range of stakeholders. And inherent with new materiality is the need to use judgment to determine whether a relevant issue or indicator is material [9], In other words, whether or not an issue becomes 'substantively influential' or 'sufficiently important' on the stakeholder interests or concerns [9] [35] [2].

\section{The Theoretical Gap}

The above literature highlights three points:

(1) Stakeholder requirements directly relate to sustainability performance. Organizational sustainability is achieved by satisfying the requirements of stakeholders.

(2) Stakeholder diversity is the basic assumption of stakeholder theory. The diversity reflects on the divergent and conflicting interests and values of stakeholders on sustainability issues.

(3) The measurement of "new materiality of sustainability performance lies on assessing the significance of its influence on stakeholder interests.

But a theoretical gap exists in that prior research view 'stakeholders' as a whole in measuring materiality of an issue. The diversity of stakeholders is ignored or inadequately recognized in formulating sustainability materiality definition. As far as I acknowledge, prior research papers do not address the influence of diverse stakeholder interest on materiality assessment.

That leads to a question: how can we develop understanding on sustainability materiality by incorporating the view of stakeholder diversity?

Here we propose a model to address two perspectives of stakeholder diversity, which are not addressed by previous materiality definitions. The two diversity perspectives are:

(1) Different interest / concern levels in different stakeholders. That is, for a sustainability issue, some stakeholders are high interested in it, some are not interested in it.

(2) Divergent impacts on stakeholders. That is, for a sustainability issue, it may generate positive impacts on some stakeholders, but negative impacts on other stakeholders.

\section{A Hierarchic Materiality Complexity Model}


6.1 Three Situations on Materiality of Sustainability Issues

We propose 3 complexity levels of materiality assessment: the first level is of 'general consensus'; and the second is 'stakeholder consensus'; and the third is 'stakeholder non-consensus'

\section{Situation one: General consensus}

The stakeholders as a whole group demonstrate similar concerns on the issue. We identify three sections in this level:

(1.1) General stakeholders high concern on this issue, with similar view on its impacts.

(1.2) General stakeholder high concern on this issue, with conflicting view on its impacts.

(1.3) General stakeholders low concern on this issue.

Issues in section (1.1) can be assessed as 'general material' to stakeholders. Further they can be viewed as negative (or positive) material. These issues perfectly meet previous materiality definitions that take stakeholders as a whole unit in judging materiality. However, previous definitions do not address whether the issue is negative or positive to the general stakeholders. We propose two new concepts to fix the current definitions: "positive materiality" and "negative materiality".

Issues in section (1.2) can be also 'material' to stakeholders as a general group. To some extent they meet previous materiality definitions in taking stakeholders as an overall unit in assessment. But stakeholders cannot achieve the consensus on the impacts. That is, we understand this issue is material to general stakeholders, but cannot define the impacts it generates are negative or positive. We propose this new concept to fix the current materiality definition: "conflicting materiality". That is, in some cases, the issue is material to general stakeholders, however, negatively impacting on some stakeholders, positively impacting on others.

Issues in section (1.3) can be considered to be general immaterial to stakeholders. And the impacts are so insignificant that we are unnecessary to further consider the negativeness or positiveness.

\section{Situation two: Stakeholder consensus}

For these issues, consensus is not achieved in general stakeholders, but achieved in one stakeholder. We identify three sections in this level.

(2.1) An issue is high concerned by one stakeholder group, and a consensus is achieved on the impacts of this issue (negative or positive). 
(2.2) An issue is high concerned by one stakeholder group, but a consensus cannot be achieved on the impacts as negative or positive.

(2.3) An issue is little concerned by one stakeholder group.

We propose this new concept, "stakeholder materiality". This concept is to interpret the situation that an issue may not be generally material to all stakeholders, but it is material to one particular stakeholder, or some stakeholders.

For an issue in (2.1), it is negative (or positive) material to the target stakeholder.

For an issue in (2.2), it is material to the target stakeholder however conflicting views on the impacts. That is, it is conflict material to the target stakeholder.

For an issue in (2.3), it is immaterial to the target stakeholder. Its impacts are insignificant, regardless of the negativeness, positiveness and conflitedness.

\section{Situation three: Stakeholder non-consensus}

For a target stakeholder group, they neither show a distinct high concern level on the issue, nor achieve consensus on its impacts (negative or positive).

6.2 The hierarchy of materiality assessment complexity

We have a hierarchy of the materiality assessment based on the above analysis.

Complexity grade 1: issues in section (1.1) and (1.3). issues in (1.1) can be simply labeled as negative (or positive) material to stakeholders; and issues in (1.2) simply labeled as immaterial. In this grade, we can use traditional definitions or models to interpret the sustainability materiality of issues, to say, 'it is material (to stakeholders)', or 'it is immaterial (to stakeholders).'

Complexity grade 2: issues in section (1.2). These issues cannot be simply labeled negative (or positive) material, but still be judged as 'material' against the background of conflicting stakeholder opinions. In this grade, traditional definitions and models can still be applied. We say 'it is material (to stakeholders)', but we need to add, 'stakeholder views are conflicting on this issue.'

Complexity grade 3: issues in section (2.1) and (2.3). Issues in (2.1) cannot be judged as material to stakeholders as a whole; however can be judged as negative/positive material to one target stakeholder. 
Issues in (2.3) cannot be judged material or immaterial to stakeholders as a whole; but can be judged as immaterial to one target stakeholder. In this grade, traditional definitions and models are not applicable. But we can apply the new concepts, 'stakeholder materiality' and 'negative/positive materiality'. We can say, 'it is negative /positive material to this target stakeholder.'

Complexity grade four: Issues in section (2.2). They are material to one target stakeholder group, however cannot be judged negative/positive material towards this stakeholder group. Traditional definitions and models are not applicable in this grade. But we can apply the new concepts 'stakeholder materiality' and 'conflicting materiality'. Say, 'it is conflicting material to this target stakeholder.'

Complexity grade five: issues in level (3). Issues in this category cannot be judged as immaterial or material toward the target stakeholder distinctly; nor judged as negative or positive impacts on stakeholder. In this grade, the traditional models and definitions are not applicable. And our new concepts are meeting limitations in interpretation. That is, this grade is beyond our current understanding.

\subsection{Comments on the hierarchy model}

This hierarchy shows the complexity grades of materiality judgment relates to the issue category according to the extent of consensus among stakeholders. The previous materiality assessment models/definitions view materiality of issues in grade one and grade two. That is, the traditional materiality models interpret an issue as 'material or immaterial' to the whole stakeholders. From Grade three to five, situations remain unexplained and unexplored for previous materiality models.

The conceptualization of 'negative / positive /conflicting materiality' and 'stakeholder materiality' can assist to explore the new methodology of materiality assessment, by addressing the materiality of issues in complexity grades three and four. But for grade five, we will meet more complex or even confusing situations in assessing materiality. Assessment in such situation may be beyond our current knowledge, and cannot be resolved in the above new concepts that this study proposes. 


\section{Conclusion}

This conceptual paper explores how stakeholder diversity affects the materiality assessment in sustainability context. It observes a theoretical gap in prior research: the view of previous materiality models by taking all stakeholders as one unit is challenged by the view that stakeholders are diverse in their opinions and interests toward the issues.

The paper furthermore suggests the complexity levels on assessing sustainability materiality in addressing the limitations of prior models. The prior models cannot meet the requirements in interpreting materiality in high complexity levels. In seeking possible solutions on this problem, the study proposes these new concepts (stakeholder materiality; negative/positive/conflicting materiality), and explores how they can develop our interpretation on materiality in high level. Thus, exploring a new methodology of understanding and assessing sustainability materiality, this case study enriches the theories of sustainability accounting and management.

\section{Conflict of Interest}

The authors declare no conflict of interest.

\section{Reference List}

1. AccountAbility, AA1000 Assurance Standards, AccountAbility, London, 2003.

2. AccountAbility, The Materiality Report: Alighning Strategy, Performance and Reporting, AccountAbility, London, 2006.

3. Amit R \& Schoemaker R, Strategic assets and organizational rent, Strategic Management Journal 1993, 14: 33-46.

4. Barney J, Firm Resources and Sustained Competitive Advantage, Journal of Management 1991, 17: 99-120. 
5. Brenner SN \& Cochran P, The Stakeholder Theory of the Firm: Implications for Business and Society Theory and Practice, Paper presented at the Annual Meeting of the International Association for Business and Society 1991, Sundance, Utah, 1991.

6. Brundtland Commission, Our Common Future, Report of the World Commission on Environment and Development, World Commission on Environment and Development, 1987.

7. Buchholz R, Principles of Environmental Management: the Greening of Business, Prentice Hall, New York, 1993.

8. Burton B \& Dunn C, Collaborative control and the commons: safe guarding employee rights, Business Ethics Quarterly 1996, 6: 277 - 88.

9. CGA, CGA-Canada's response to the Global Reporting Initiative's G3 Guidelines, 2006.

10. Clarkson M, A stakeholder framework for analyzing and evaluating corporate social performance, Academy of Management Review 1995, 20: 92-117.

11. Dimitrov RS, Inside UN Climate Change Negotiations: the Copenhagen Conference, Review of Policy Research 2010, 27: 795-821.

12. Donaldson $\mathrm{T} \&$ Preston $\mathrm{L}$, The stakeholder theory of corporation: concepts, evidence, and implications, Academy of Management Review 1995, 20: 65 - 91.

13. Elias A, Jackson L \& Cavana Y, Changing positions and interests of stakeholders in environmental conflict: a New Zealand transport infrastructure case, Asia Pacific View Point 2004, 45(1): 87 104.

14. Flak L, Nordheim S \& Munkvold B, Analyzing stakeholder diversity in G2G Efforts, E-Service Journal 2000, 6 (2): 4 - 20. 
15. Foley K, Meta-management: A Stakeholder / Quality Approach to Whole-of-enterprise Management, SAI Global, Sydney, 2005.

16. Freeman R (1984) Strategic Management: A Stakeholder Approach, Pitman Publishing, Massachusetts.

17. Garvare R \& Johansson P, Management for sustainability: a stakeholder theory. Total Quality Management Business 2010, 21(7): 737 - 744.

18. Global Reporting Initiatives (G3), Sustainability Reporting Guidelines: 1.1 Defining Report Content, 2011.

19. Grant R M, Contemporary Strategy Analysis, Blackwell Publishers, Cambridge, MA, USA, 1995

20. Harrison J \& St John C, Strategic Management of Organizations and Stakeholders, West Publishing, 1994.

21. Hill C \& Jones G, Strategic Management Theory: An Integrated Approach, Houghton Mifflin, Boston, USA, 1992.

22. King W \& Cleland D, Strategic Planning and Policy, Reinhold Publishing, New York, 1979.

23. Kohli A \& Jaworski B, Market orientation: the construct, research propositions, and managerial implications, Journal of Marketing 1990, 54 (2): 1 - 18.

24. Lamberton G, Accounting for sustainable development: a case study of city farm. Critical Perspectives on Accounting 2000, 11(5): 583 - 602.

25. Lamberton G, Sustainable sufficiency - an internally consistent version of sustainability, Sustainable Development 2005, 13, 53-68. 
26. Mahoney J \& Pandian J, The resource based view within the conversation of strategic management, Strategic Management Journal 1992, 13: 363 - 380.

27. Mitchell R, Agle B \& Wood D, Toward a theory of stakeholder identification and salience: defining the principle of who and what really counts, Academy of Management Review 1997, 22(4): 853 886.

28. Ogden S \& Watson R, Corporate performance and stakeholder management: balancing shareholder and customer interests in the U.K. privatized water industry, Academic of Management Journal 1999, 42(5): $526-538$.

29. Pearce D, Barbier E \& Markandya A, Sustainable Development: Economics and Environment in the Third World, Edward Elgar, Aldershot, UK, 1990.

30. Rhenman E, Industrial Democracy and Industrial Management: A Critical Essay on the Possible Meanings and Implications of Industrial Democracy, Tavistock, London, 1968.

31. Sadler B \& Armour A, A common ground: on the relationship of environmental assessment and negotiation, in The Place of Negotiation in Environmental Assessment, 1 - 6, Canadian Environmental Assessment Research Council, Ottawa, Canada, 1987.

32. Signitzer B \& Prexl A, Corporate sustainability communications: aspects of theory and professionalization. Journal of Public Relations Research 2008, 20(1): 1-19.

33. Weiss R, Cracks in the foundation of stakeholder theory, Electronic Journal of Radical Organization Theory 1995, 1 (1), Retrieved from www.mngt.wikato.ac.nz/ejrot/Vol1_1/weiss.pdf

34. Wilson M, Corporate Sustainability: what it is and where does it come from? Ivey Business Journal 2003, March/April: $1-6$.

35. Zadek S \& Merme M, Redefining Materiality, AccountAbility, London, 2003. 
(C) 2011 by the authors; licensee MDPI, Basel, Switzerland. This article is an open access article distributed under the terms and conditions of the Creative Commons Attribution license (http://creativecommons.org/licenses/by/3.0/). 